\title{
The Role of the Physical Environment in Supporting Organizational Creativity
}

\author{
Supaporn Vithayathawornwong, M.S., Sheila Danko, M.I.D., and \\ Pamela Tolbert, Ph.D. \\ Cornell University
}

\begin{abstract}
Creativity has been underscored as a key factor to organizational adaptability and competitiveness in today's rapidly changing business environment. Designing as well as managing work environments that facilitate creativity have therefore received growing attention, resulting in a multitude of research examining the social-psychological work environment. Few

studies, however, have focused on the contribution of the physical work environment to supporting creativity in the workplace. This study focuses on the role of the physical environment in supporting creativity in organizations by identifying specific physical features and attributes of the work environment perceived to promote or inhibit creativity. The research design compares four organizations publicly acclaimed for their innovative social-psychological work environments, but which are distinctly different in terms of the physical work environment. Quantitative and qualitative data were collected by means of survey questionnaires [ $N=130$ ). Results indicate that the physical work environment exerts indirect influence on creativity by contributing to two significant social-psychological conditions that are conducive to creativity, namely dynamism and freedom. The study specifies attributes of the physical work environment perceived to be positively and negatively associated with both of these conditions.
\end{abstract}

Introduction

The rapid technological advances of the twentieth century forced a dramatic change in global business environments and organizational structures, from an era of mass production and bureaucratic organizations to one of mass customization and virtual organization. In order to remain competitive in this era of rapid change, organizations must shift from a dependence on bureaucratic consistency and efficiency to a reliance on organizational adaptability and competitiveness, of which creativity and innovation are key concepts (Basadur, 1997). But how should organizations nurture creativity and innovation?

Mumford and Simonton (1997) argued that the workplace represented one of the most promising venues for studying creativity. However, the majority of literature on the subject predominantly focuses on the socialpsychological work environment, commonly referred to as the organizational climate for creativity, (Amabile, 1996; Ekvall \& Tangeberg-Andersson, 1986; Ekvall, Arvonen \& Waldenstrom-Lindblad, 1983; Fischer \& Farr, 1985; Hitt, 1975; Litwin \&C Stringer, 1968; Cummings, 1965; Nystrom, 1979) while only a handful of studies pertaining to the role of the physical work environment on creativity are evident. Understanding how the social psychological and physical environments work together to support creativity in the workplace is an important next step in evolving the knowledge base on organizational creativity; such knowledge would position architects, designers, and planners as strategic players in enhancing corporate competitiveness.

\section{Literature Review}


A premise at the heart of environmental psychology posits that all behavior occurs within a socio-physical realm (Clitheroe, Stokols \& Zmuidzinas, 1998; Magnusson, 1981). Accordingly, behavior cannot be understood in isolation from its context. From this realization, creativity can be viewed as a complex and multifaceted system spanning person, process, product, and press (environment) (Rhodes, 1961). Historically, creativity scholarship into the environment has been given relatively little attention when compared to the number of psychologically based studies which focused on identifying traits of creative individuals (Guilford, 1950, 1967; MacKinnon, 1962). However, more systemic approaches have emerged that account for diverse environmental influences on an individual's creativity. Mumford \&C Gustafson (1988) concluded that creative behavior is likely to be determined by complex interactions between attributes of the individual and his or her environment. Amabile's (1983, 1998) social psychological theory of creativity evolves this idea one step further to state that creative performance is a result of not just the individual interacting with his or her environment, but a broader interplay between collective social and environmental factors and the individual. Gruber (1988) and later Csikszentmihalyi $(1988,1999)$ expand on Amabile's theory by describing creativity as a system of social interactions between the individual, the field (or social environment) and the domain (or cultural environment). This evolution of creativity theory recognizes an increasing need to examine creativity as a function of the interrelationships between the individual, the organization, and the physical environment.

\section{Organizational Creativity and the Social-Psychological Work Environment (SWE)}

Studies by Ekvall and his associates (Ekvall, Arvonen \&c Waldenstrom-Lindblad, 1983; Ekvall \& TangebergAndersson, 1986) have identified several social-psychological dimensions of creative organizational climate. Based on their 50-item Creative Organizational Climate Questionnaire (Ekvall et al, 1983), factor analyses of responses from a group of over 500 researchers, engineers, and marketing personnel in several studies yielded nine major dimensions of creative organizational climate as follows:

1. Challenge: the degree to which employees are personally challenged in daily operations.

2. Idea Support: the way in which new ideas are received and retreated.

3. Trust: the degree of emotional safety that employees experience in their working relationships; when there is high trust, new ideas surface easily.

4. Freedom: the degree to which individuals are given latitude in defining and executing their own work.

5. Dynamism: the degree of energy and activity within the organization.

6. Tension and Conflicts: the degree to which employees engage in interpersonal conflicts.

7. Debates: the degree to which employees feel free to debate the issues actively, and the degree to which minority views are expressed readily and listened to with an open mind.

8. Risk Taking: the degree to which employees feel free to make mistakes when trying out a new idea; the degree to which ambiguity is tolerated.

9. Playfulness and Humor: the degree to which there is spontaneity and employees are at ease. 
Empirical research aimed at identifying dimensions of creative organizational climates has been conducted by several other scholars. For example, Fischer and Farr (1985) applied Rickard and Bessant's (1980) Creativity Audit Questionnaire in Chinese R\&D units and determined five dimensions of innovative climate: commitment to innovation, group process and cohesiveness, planning responsibility and autonomy, inertial tendencies, and group dynamism. Siegel and Kaemmerer (1978) developed a 61-item questionnaire to study the perceived organizational support for innovation. Factor analysis of responses from almost 2,000 high school teachers and students revealed one major factor, support of creativity, and two smaller factors, tolerance of diversity among members and personal commitment to the organization, as important dimensions in innovative climates.

Taken together, dimensions of the social-psychological work environment suggested by the literature can be summarized along an individual-interpersonal-organizational continuum. Recurring factors that fall toward the individual end of the spectrum are commonly task-related, including challenge, freedom, autonomy, sense of control, recognition, and reward. Factors that cluster at the interpersonal level involve communication, relationships, information sharing, trust, peer support, group dynamism and interaction, and group composition and cohesiveness. At the organizational level of the continuum are provision of resources, management policies, organizational support, organizational structure, and an atmosphere that promotes risk-taking.

\section{Organizational Creativity and the Physical Work Environment (PWE)}

Alencar and Bruno-Faria (1997) point out in their creative climate study that the physical work environment has not received much empirical attention. However some theoretical underpinnings exist. Kanter (1988) suggested that physical layout can facilitate individual creativity and innovation. Tesluk, Faar, and Klein (1997), in their literature review of influences of organizational climate on individual creativity, concluded that intangible organizational values, beliefs, and assumptions, from which organizational climate arises, are reflected in more tangible aspects of the organization such as patterns of behavior, organizational structure, and physical work environment. These tangible aspects articulate and reinforce the underlying value and belief structures that characterize an organization. Schein (1990) suggests that within organizations where creativity is highly valued, one would likely observe a configuration of the physical environment that connotes equality and facilitates interpersonal interaction.

Ekvall and Tangeberg-Andersson (1986) conducted a case study of an innovative Swedish newspaper office to examine the working climate for creativity. Their analytical framework included the physical work setting as a contributing factor to creative climate among other situational factors such as leadership, strategies, values, vision, and goals. The study identified spatial arrangements as a determinant of creativity. Employees reported that the move from an open plan office to partitioned offices negatively affected discussions, playfulness, and information exchange. However, working in private offices enhanced freedom, improved the quality of information, and made work disciplines easier.

The absence of a direct, simplistic causal link between the physical work environment and creativity necessitates alternative means of conceptualizing and operationalizing the relationship between the two constructs. One way to conceptualize the influences of the physical work environment on creativity is to assign the social-psychological work environment as a mediator. This study proposes that the physical work environment influences creativity by contributing to certain social-psychological conditions of the work environment that are conducive to creativity. Figure 1 graphically presents this proposed relationship. Compared to prior research, this conceptual premise provides an alternate framework for investigating the role of the physical work environment in supporting an organizational climate for creativity. 


\section{Research Objectives}

The study presents two principal objectives through first exploring the perceived relationship between the social-psychological work environment (SWE) and the physical work environment (PWE), the two dimensions of the total work environment that operate as a contextual factor to creativity in organizational settings. The findings will explain specific social-psychological conditions supported by the physical work environment under which creativity in the workplace is promoted. Secondly, the study seeks to identify specific elements and attributes of the physical work environment that are perceived to promote or inhibit creativity in organizational settings. The research findings will contribute to a better understanding of how environmental designers and planners can manipulate the physical work environment to promote creativity in the workplace.

\section{Figuro 1}

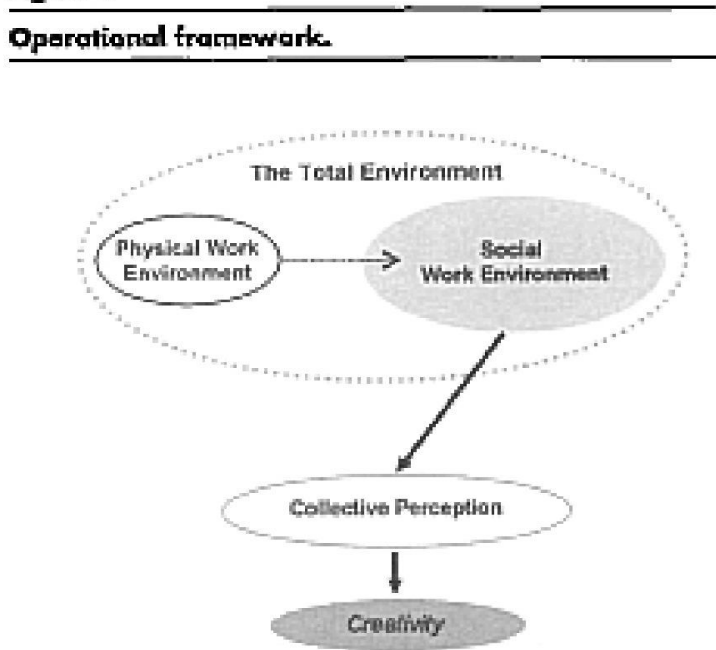

\section{Methodology}

\section{The Research Sites}

The research was conducted in four mid-to large-sized organizations recognized for their innovative work practices and initiatives. Research sites were selected from two sources. The first source was the George Land World Class Innovator Award Winners poll. This award was established by the Innovation Network, a professional association of business leaders dedicated to promoting organizational effectiveness via innovation and creativity. The second source consulted recent news articles identifying firms with innovative organizational practices.

It is important to note that none of the four organizations were distinguished or received public acclaim for the innovative design of their physical spaces. While the spaces were different in function and scale, the level of design for each organization's physical spaces across all four organizations was consistent in that spaces were ordinary and aesthetically undistinguished. Such ordinary space was an important aspect of the selection criteria ensuring that the design was relatively uniform and homogeneous providing a more controlled basis for comparisons. 
Organization A, a George Land Innovator Award winner, is a regional headquarters of a renowned international non-profit organization that provides a comprehensive network of community-oriented, familycentered services, mainly sports and recreational services. Eighty employees, engaged in the administration of this non-profit, occupy four stories of a high-rise building in a major metropolitan area in the central United States. The physical work environment is a typical open-plan configuration with cubicle workstations individually assigned to managerial and general staff. All cubicles are enclosed with $5 \mathrm{ft}$ high dry wall or movable partitions. A small number of private offices with floor-to-ceiling enclosure are provided for the management.

Organization B, also a George Land Innovator Award winner, is located in a large western city with approximately 2,000 employees representing a more complex corporate healthcare work environment spread across three interconnected buildings. The physical work environment consists of designated departmental work areas and common public facilities including a cafeteria, lobby spaces, open courts, and an auditorium. A typical floor includes a public lobby with a central reception desk or nursing station surrounded by examination rooms and other service and support spaces. Provided in every departmental area is at least one small break/lunch room.

Organization $C$ is a software development company located in a mid-sized city in the Northeast, employing approximately 60 people. Organization $C$ is located in a domestic-scaled corporate building with conventional workplace configuration consisting of small private offices; each is fully enclosed with floor-to-ceiling walls. Most offices are shared by a few employees. Common public areas include conference rooms and meeting areas, centralized copy facilities, and a lunch room with small kitchen.

Organization D is also a software developer company in a mid-sized city in the Northeast, employing approximately 40 people within a domestic-scaled corporate building. The building has open-plan offices with individually assigned cubicle workstations arranged in an open area with a few private offices for management. Organizations $C$ and $D$ were selected based upon recent news articles identifying them as embodying innovative organizational practices.

\section{Subjects}

In the three mid-sized organizations (Organizations A, C, and D), all full-time, office-based employees were included in the sample. In the large organization (Organization B), systematic random sampling of the 2,000 employees was utilized. At response rates of $52.15 \%$ and $31.25 \%$ for the mid-sized and large organizations respectively, the final sample that provided usable data consisted of 130 full-time employees, including 13 employees from Organization A, 50 from Organization B, 38 from Organization C, and 29 from Organization D. Demographic information of participants is shown in Table 1.

Instrument

To investigate the relationship between the social-psychological work environment (SWE) and the physical work environment (PWE), a two-part questionnaire was developed to assess the organizational climate for creativity and to investigate the theoretical components. The questionnaire was keyed to allow the researchers to seek out a respondent for further elaboration on substantive issues that surfaced.

Part 1: Assessing the Social Work Environment (SWE) 
This component of the questionnaire measured the employees' perception of how supportive their overall social-psychological work environment is to creativity. According to Ekvall (1987), perception and cognition serve as the mediating links between organizational contexts and behavior. Organizational climate is thus appropriately measured through the perceptions of organizational members. The SWE assessment was based on the

[Table 1]

Creative Climate Questionnaire, previously developed by Ekvall, Arvonen and Waldenstrom-Lindblad (1983) for the Swedish Council for Management and Organizational Behavior. The assessment was significantly redesigned and reformatted for the purpose of this study. Three categories from the original questionnaire, Risk Taking, Debate, and Humor were omitted, while the item Freedom was divided into two items: Freedom in the Job and Freedom in the Organization. The resultant SWE instrument contained 50 items measuring seven factor indices of the creative (social-psychological) organizational climate as follows:

1. Challenge: "The operation as a whole is stimulating and engaging."

2. Support for ideas: "New ideas are supported and encouraged."

3. Trust: "People do not talk about each other behind their backs."

4. Freedom in the organization: "You are allowed to make your own decisions."

5. Freedom in the job: "You can take an extra break if you want to."

6. Dynamism: "There is always something going on here."

7. Tension: "There is an unusual mix of view and opinions."

Participants rated each dimension on a seven-point Likert scale by indicating the extent of their agreement with each item. The instrument has been proven to possess good reliability and validity in discriminating creative organizational climate, with Cronbach's coefficient alpha scores ranging from .67 to .92 .

Part 2: Assessing the Physical Work Environment (PWE)

This assessment, developed by the researcher, parallels the SWE and evaluates how supportive the physical work environment is to the social-psychological climate for creativity. Based on the literature of Ekvall et al. (1983), three theoretical components of creative organizational climate were identified and taken as a hypothetical starting point in designing the PWE assessment instrument:

1. Dynamism: "This physical work environment induces life and enthusiasm in my job."

2. Freedom and autonomy: "This physical work environment makes it possible for me to choose my own work rhythm."

3. Trust and open relationships: "This physical workplace encourages open relationships among employees."

Based on Sundstrom (1986), the operational definition of the physical work environment (PWE) is given in the questionnaire as "the interior architectural surroundings of you and your entire organization, including: the 
appearance and arrangement of spaces (work areas, meeting areas, circulation, social spaces, and other support and service spaces); furniture, furnishings, equipment, and accessories; and the associated ambient conditions

Tatele 2

\begin{tabular}{|c|c|c|c|}
\hline Opgnibulion & Moust & 50 & $N$ \\
\hline$A$ & 1.07t & .78 & 13 \\
\hline$g$ & $3.7 \Delta 7$ & .728 & 50 \\
\hline$c$ & 4.783 & .724 & 和 \\
\hline D & 3.999 & 9.128 & 29 \\
\hline
\end{tabular}

Toblc두 7

\begin{tabular}{|c|c|c|c|c|}
\hline \multicolumn{5}{|c|}{ Past hoe pairwist comparisonst of nean SW/ zeofes } \\
\hline 川 & ! & $\| \cdot \hat{0}$ & & \\
\hline ng & $\mathrm{gm}$ & wan Diflgono & sol. Fala & 30 \\
\hline$\dot{A}$ & $\begin{array}{l}\text { B } \\
6 \\
0\end{array}$ & $\begin{array}{l}721921 \\
7045017 \\
1094 \%\end{array}$ & $\begin{array}{l}200147 \\
20679 \\
.279226\end{array}$ & $\begin{array}{l}579 \\
.044 \\
.05\end{array}$ \\
\hline a & 5 & $\begin{array}{l}-1.070405+ \\
-14204 d\end{array}$ & $\begin{array}{l}.180010 \\
.105270\end{array}$ & .60 \\
\hline 5 & 0 & .094701+ & $20627 \mathrm{E}$ &.$\infty 0$ \\
\hline
\end{tabular}

(light, sound, temperature, air)." From the given definition, it is worth noting that the scope of the PWE in this study encompasses the entire built environments of an organization rather than the simply immediate, primary workspace of an individual.

The instrument was pilot-tested and revisions were made to ensure the understandability and clarity of the instructions and items. A reliability analysis further eliminated items that had low item-item and item-total correlations. The resultant PWE instrument contained 23 items to measure the perceived impact of the physical work environment on the three components of Dynamism, Freedom, and Trust. Cronbach's coefficients alpha indicated an internal consistency of .94 for dynamism, .66 for freedom, and .60 for trust.

\section{Procedures}

Paper-based questionnaires, including a brief introductory letter and a postage-paid return envelope were mailed to Organizations $A$ and $B$; an identical introductory e-mail was sent to Organizations $C$ and $D$ with a link to an identical internet-based questionnaire. All participants were allowed three weeks for submittal of their responses. Upon completion of primary data collection, the researcher conducted one on-site walkthrough at each of the four research sites to gather supplementary data. The objective of the site visits was to visually document the existing physical work environment and to conduct informal interviews with selected employees whose responses to the questionnaire yielded information that invited further inquiry. The application of the data collected from the site visit exercise was used to clarify and confirm the primary data, hence providing more indepth understanding and insight into the subsequent data analyses.

\section{Results}

Global SWE Index Scores 
Mean values of the 50 SWE assessment responses were calculated to yield a single global SWE index score for each respondent and each organization. The global SWE index scores for the four organizations are presented in Table 2. A one-way analysis of variance indicated significant mean differences between the four organizations,

Tolo 4

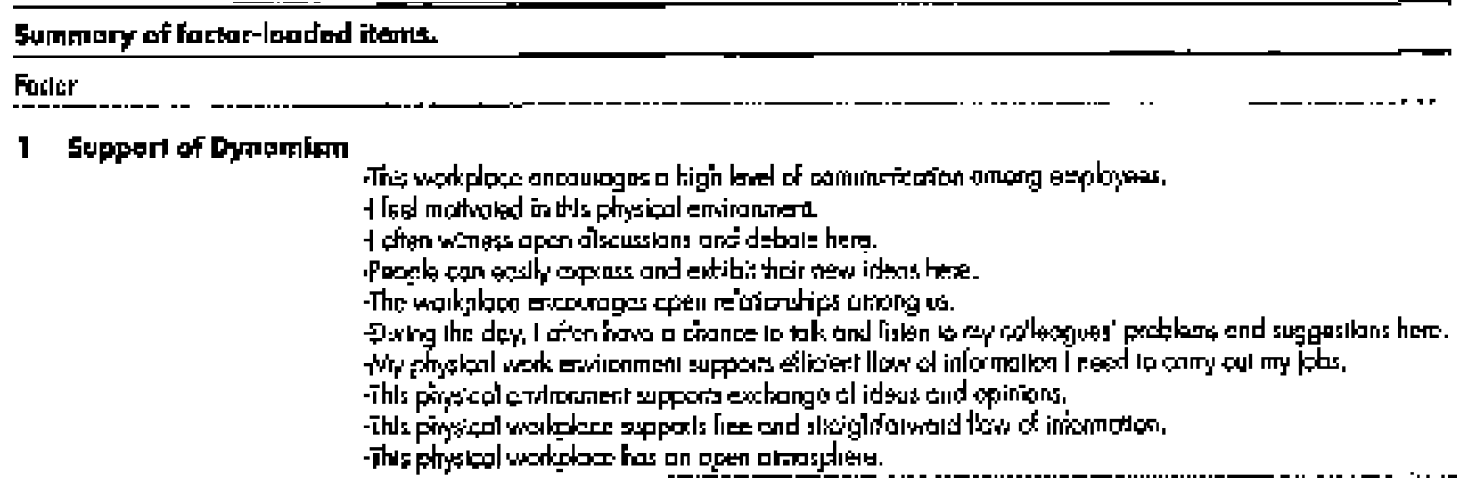

2 support of Frodom

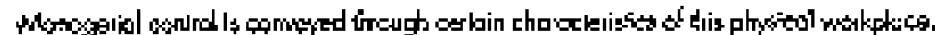

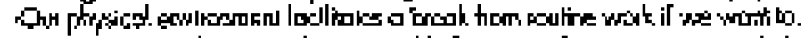

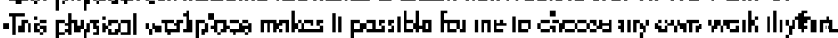

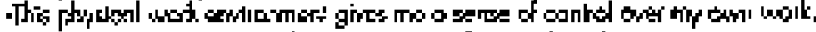

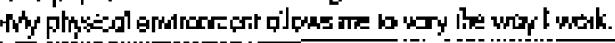

$F(3,126)=12.022, p<.001$. Pairwise comparisons indicated that Organization $\mathrm{C}$ had a significantly higher social work environment index score than the other three organizations, indicating elevated employee perceptions that the social work environment within their organization was supportive of creativity (see Table 3 ).

\section{PWE Factor Analyses}

The 23 PWE survey items were analyzed using principle component factor analysis and varimax orthogonal rotation to identify meaningful components for interpretation. As a result of the first two factor analyses, six items that loaded on more than one component were eliminated. From the third factor analysis, two factors underlying the remaining 17 items were extracted accounting for $58.02 \%$ of the total variance.

Interpretation of the factor analyses yielded two PWE factors designated as: Support of Dynamism and Support of Freedom accounting for $37.96 \%$, and $19.06 \%$ of the variance respectively. Cronbach's alphas computed from the final set of data were .94 for Support of Dynamism and .64 for Support of Freedom. To provide the reader with further insight, questionnaire items relating to these two salient PWE factors are summarized in Table 4.

\section{PWE Factor Scores}

PWE factor scores for Support of Dynamism and Support of Freedom are presented for each organization in Table 5. A one-way ANOVA found significant mean differences among the participating organizations for both PWE factors: Support of Dynamism $F(3,121)=4.335, p<.006$, and Support of Freedom $F(3,121)=5.774, p<.001$. 


\section{Table 5}

\begin{tabular}{|c|c|c|c|c|}
\hline $\begin{array}{l}\text { Metrht ant } \\
\text { grares. }\end{array}$ & tster & $\mathrm{ta}$ & 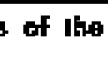 & \\
\hline & 5tFpot & nकाiem & 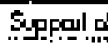 & 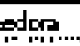 \\
\hline 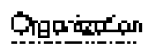 & החי & $s$ & Mern & 50 \\
\hline$M$ & -192 & 1.325 & -2.90 & . \\
\hline a & -106 & |. & - & 1.64 \\
\hline 5 & .48 & .055 & .209 & 944 \\
\hline ㅁ. & -24h & 1.tou & ड़ts & . 的昰 \\
\hline
\end{tabular}

To account for the variation in the PWE scores between each organization, post-hoc pairwise comparisons were conducted. Results of this analysis, presented in Table 6, indicate that Support of Dynamism within Organization $C$ was significantly higher than Organizations $B$ and $D$, and that Support of Freedom within Organizations $C$ and $D$ was significantly higher than Organization $B$.

\section{Correlations between the SWE and the PWE Factors}

To determine the relationship between the social-psychological climate for creativity and the physical work environment, Pearson Product-Moment Correlation Coefficients were computed among the global SWE index scores and the two PWE factor scores. The correlation matrix in Table 7 indicates significant correlations between the SWE and Support of Dynamism $\{r=.587, p<.001)$, and the Support of Freedom $(r=.450, p<.001)$.

These results suggest that, within organizations in which the social-psychological work environment is perceived to be more supportive of creativity, the physical work environment is also perceived, in terms of dynamism and freedom, to be conducive to creativity as well; while the inverse is perceived within organizations less supportive of creativity.

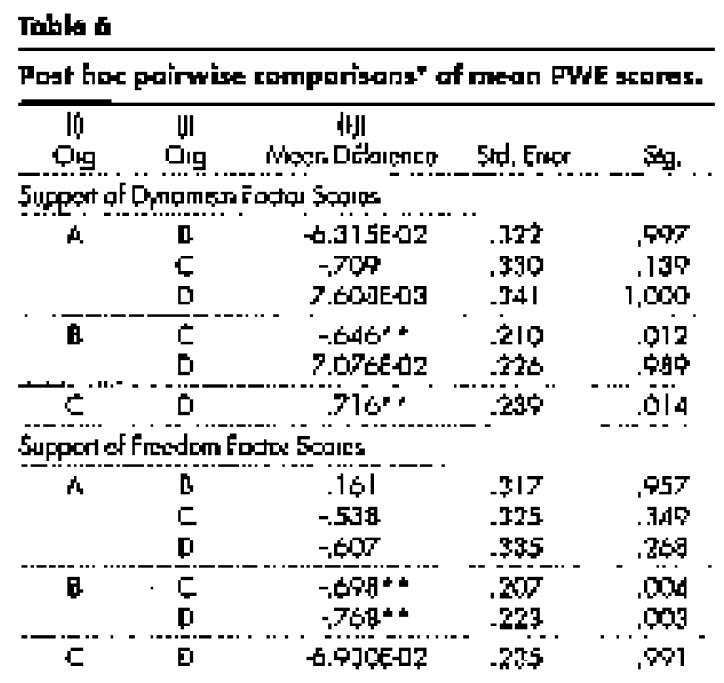

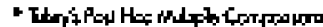

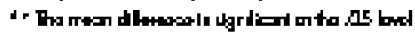

\section{PWE Content Analysis of Descriptive Responses}

Of the 130 subjects, $71 \%$ \{ $n=92$ ) gave at least one written comment describing specific elements or attributes of their physical work environments that attributed to their strongly positive or negative rating response 
to selected questionnaire items. All valid qualitative comments were coded into 18 categories associated with an organizational climate for creativity: 1) general office layout, spatial arrangements and spatial configuration; 2) size of office or workspace; 3) enclosure of office or workspace; 4) access to colleagues and resources; 5) provision of congregation space; 6) provision of stretch-out facilities or break areas; 7) provision of storage space; 8) location or neighborhood; 9) general physical conditions of furniture and equipments, e.g., new, old, cramped; 10) presence of windows; 11) decorative features, including color, materials, art objects, wallpaper, accessories, and so on; 12) general visual and emotional appeal, concerning the pleasant, informal, friendly, and homey nature of the work atmosphere; 13) supportive technology, e.g., voice mail system, electronic mail, telephone and paging system, internet, etc.; 14) openness of atmosphere; 15) proximity; 16) territoriality; 17) egalitarianism; and 18) personalization.

Using the eighteen categories identified above, further content analysis was conducted to identify which specific physical attributes were most frequently perceived to impact organizational climate for creativity. Table 8 reports the relative frequency of these specific PWE elements found to be associated with Support of Dynamism and Support of Freedom.

\section{Discussion}

The findings indicate that the social-psychological work environment (SWE) and the physical work environment (PWE) are perceived to collaboratively constitute the total environment influencing creative behavior. Correlations between the global SWE index score and two PWE factors, Support of Dynamism and Support of Freedom, imply that the operational role of the physical environment in promoting creativity in organizations is primarily mediated by the social-psychological work environment. The physical work environment exerts its indirect influences on creativity by facilitating two significant social-psychological conditions that are conducive to creativity, dynamism, and freedom. Figure 2 diagrams the relationship of the findings.

According to the literature review of creative organizational climate, the social-psychological dimensions of the work environment supportive to creativity are summarized along a continuum of individual-interpersonalorganizational level of operation. Regarding this categorization, dynamism is a single social-psychological dimension found to be associated with the physical work environment at the interpersonal level. Also, at the individual level, freedom represents a dimension affected by the physical work environment. No socialpsychological dimension at the organizational level was found to reflect the influence of the physical work environment in this study.

[figure 2]

\section{Dynamism}

The data from this study suggests that dynamism is the most salient social-psychological condition conducive to creative behavior supported by the physical work environment. Dynamism embraces several sub-dimensions including interpersonal interaction, communication, and information and idea exchange.

Results have shown that the physical work environment of Organization $C$ was perceived to be most conducive to dynamism among those of all participating organizations. Therefore, the physical characteristics of Organization $C$ in comparison to those of the others may shed some light on deciphering specific features of the physical work environment that support dynamism. Results of the content analysis of perceived physical features 
associated with dynamism may then help construct a framework of analysis which discloses attributes of the physical environment that support creativity.

With respect to the content analysis conducted on qualitative responses, layout and spatial arrangements, enclosure of office or workspace, and accessibility together contribute to approximately half of all descriptive comments pertaining to dynamism. These features are considered interdependent; in other words, in arranging cubicle workstations with partitions in an open area, the nature of enclosure and accessibility is simultaneously identified. Thus, comprehensive analysis of these intertwined features might yield more meaningful implications than analyses of isolated features. It is also worth noting that no ambient conditions of the physical environment, e.g., temperature, air quality, or acoustic quality, are mentioned to be associated with dynamism.

Proximity ranks third among the most frequently mentioned physical characteristics relevant to dynamism (9.6\%). This result is consistent with prior studies (Allen, 1969) where frequency of communication declined as a function of the distance between workspaces. Sundstrom (1986), in reviewing empirical studies concerning the relationship between proximity and interpersonal contact in the workplace environment, concluded that the findings differed for formal and informal communication. In sum, for people in the same building, inter-workspace proximity generally has little to do with work-related, face-to-face contact; however, evidence indirectly suggests that inter-workspace proximity is associated with the amount of contact between supervisor and supervisee. Close proximity among workspaces is associated with informal conversation. People tended to converse with their closest neighbors and often make friends with them.

Organization $C$ possesses several intertwined physical characteristics that, taken together as an integrative environment, account for the highest score in dynamism. In a compact, domestic scaled building, fully enclosed private offices are commonly shared by a few employees. Considering the physical enclosure per se, although separate rooms are less likely to promote face-to-face interaction in comparison to the open-plan office, the presence of coworkers in unobstructed shared space, together with the "open door" policy, seems to override the effect of compartmentalization and separation among the co-workers. As a result, the arrangements contribute to greater flexibility over open-plan office in terms of type of interaction. The overall work environment facilitate both informal conversation and work-oriented face-to-face communication. The findings emphasize the issue of the quality of social contact addressed earlier by Steele (1973). Excerpts of descriptive comments from several different respondents are shown below:

Because we share offices with other people, we not only have exposure to the people that we work with on a day-to-day basis, but also to the people that come in to work with our office mates. We get exposure to people we wouldn't ordinarily get exposure to.

We can have open discussions here because there is the opportunity to close doors when necessary (not always an option in cube-oriented offices) and also because the structure lof the building] is such that it has a more "homey" feeling. People feel comfortable stopping by others' offices to talk about things.

We're pretty much co-located down two hallways. Most doors open to a hallway with a blank wall on the opposite side so privacy isn't a concern. There're plenty of hallway conversations.

In Organization C, proximity, another major condition that promotes dynamism, is accomplished by the compact size of the building and the relative location of offices connected by clear circulation paths. These factors 
also provide ease of access among separate offices. The descriptive data, however, provides no clear indication of the type of interaction promoted by such proximity:

Due to the compactness [of the office building] everyone is close by allowing for frequent interaction with coworkers. Can just call across the hall.

Mostly... the person you need to talk to is just around the corner, and probably has their door open.

With regard to Osmond's (1966) socio petal physical settings, provision of meeting spaces and gathering places outside workspaces encourages a high level of face-to- face communication, e.g., corridors, cafeteria, photocopying rooms, mail rooms, bulletin boards, coffee pots, or vending machines. The ideal characteristics of a gathering place include convenient accessibility to workspaces and a comfortable setting for conversation (Sundstrom, 1986). Bechtel (1976) added that it should be an activity node, a place where peoples' paths cross during their regular, daily activities. These conditions are present in the physical environment of Organization $C$, as shown in the following excerpts:

Offices are a nice size so you can conduct small meetings in your office.

There are numerous conference rooms to have quick informal meetings. I often see discussions from my office due to its location close to the landing at the top of the stairs. This is where the printers are located so people are often meeting each other here and they start discussing various different topics. It is the grand central station of our office.

However, employees of Organization C also reported certain negative aspects of separate, shared offices on interaction and other work-related issues such as productivity:

The way our workspace is divided into small offices can actually make it hard to talk to someone. I hesitate to go to an office in case I am interrupting something. Because the environment is so open, coworkers are always talking about problems and suggestions, but the talk is not always productive.

Integrating other participating organizations into the frame of analysis reveals an interesting issue of the effects of conventional office (presented in Organization C) as opposed to open-plan office (presented in Organizations A, D and some departmental areas of Organization B) on dynamism. Among open-plan office advocates, a prevailing assumption has been that the arrangements encourage greater interaction and communication in the workplace. A large number of post-occupancy evaluations of open-plan arrangements have been conducted and comprehensive reviews of these studies by Becker (1981), Sundstrom (1986), and Ferguson and Ferguson (1988) consistently pointed out that the results of the introduction of open-plan offices were mixed. However, a tendency was manifested toward increased communication in general through greater visual accessibility and decreased communication of a more intimate, confidential nature as a result of privacy loss, increased distractions, and interruptions. In other words, relocation to open-plan offices may result in a greater amount of communication yet poorer quality of interaction. To some extent, the descriptive findings of this study appear to replicate the perspective of these earlier studies. Evidence provided by employees working in open-plan offices demonstrated mixed perceptions of the open-plan arrangements as related to interaction and communication: 
Work "cubes" set up with peers working on similar projects in adjoining areas. Cubes do not have doors or full height walls, therefore discussion, problem solving, and opinions often flow from person to person and group to group. Others in nearby workspaces often visit other areas with work concerns, questions, and problems.

Cubicles are not a physical environment that encourage communication. They are the cause of constant interruption, lack of privacy, suppression of ideas. They are just a bad idea. Due to the structure of the cubicle environment, you sometimes hear or OVERHEAR each other's PERSONAL problems and issues. This is not a good thing. There is not enough privacy in the cubicle areas.

In addition to the aforementioned group of major physical categories pertaining to workspace arrangements and their properties, content analysis revealed other peripheral physical characteristics that were perceived to affect dynamism, although to a lesser degree. For example, comments regarding windows address negative psychological effects of windowless workplace in terms of lack of view and visual contact to the outside environment; the findings are consistent with earlier anecdotal evidence from an informal series of interviews with occupants of windowless offices conducted by Sommer (1974). Supportive technology concerns included the provision of electronic communication systems and equipment that facilitated the flow of information and intraorganizational communication, e.g., voice mail system, electronic mail, telephone, and paging systems.

\section{Freedom}

Freedom, basically involves several sub-dimensions, autonomy, sense of control (over one's work), and freedom from control. Proshansky, Ittelson, and Rivlin (1970) proposed that in any situational context, one attempts to organize the physical environment so that it maximizes one's freedom of choice; therefore, a physical setting should provide many alternatives for satisfying this need. Applying this concept to the present study implies environments that provide not only work-related space but also spaces for alternative, non work-related functions as well. The findings support the provision of stretch-out facilities and break areas as the most frequently mentioned category of the physical work environment associated with freedom (27.78\%).

Proshansky et al (1970) further suggested two specific physical characteristics relevant to freedom of choice, privacy, and territoriality. Privacy serves to maximize freedom of choice by permitting the individual to feel free to behave in a particular manner; whereas territoriality enables the ability to control what goes on in defined areas of space. Literature supports the contribution of personalization to freedom (Sundstrom, 1986). Personalization-the decoration, modification, or rearrangement of an environment by its occupants to reflect their individual identities-expresses the amount of freedom and control the organization allows the individual to exert over the workspace. However, this factor was mentioned to a minimal degree in this study (3.7\%).

Data indicated that the physical work environment of Organization $D$ is perceived to be most conducive to creativity. Taking privacy and territoriality as the criteria, there seems to be no doubt that Organization $C$, with its conventional, fully-enclosed office arrangements, scored relatively high in freedom. Yet the fact that Organization D which adopts the open-plan office arrangements scored slightly, though not significantly, higher than Organization $\mathrm{C}$ would generate an interesting debate relative to creativity.

According to Oldham and Brass (1979), the socio-technical approach to the influences of the physical setting argues that boundaries can transform a work area into a private, defensible space in which an individual 
experiences a sense of privacy. This approach implies some negative effects of open-plan offices on freedom and autonomy; occupants of open-plan offices are likely to perceive less freedom and autonomy than those of conventional offices because the absence of private offices and interior walls increases the likelihood that supervisors and coworkers will infringe upon their discretion and freedom to work (Becker, 1981). The highest score in freedom of Organization D (open-plan) to some extent contradicts these theoretical suppositions. There is no proof, and it is not the specific intention of this study to prove, that the open-plan arrangements are supportive or obstructive to freedom; it is more convincing to consider the physical aspects of Organization $D$ as a collaborative whole. Despite the hypothesized negative consequence of the open-plan offices on freedom and autonomy, the content analysis of descriptive evidence suggests that some physical characteristics of Organization D might overpower or mitigate the effect of the open-plan arrangement. The provision of stretch-out facilities and break areas contributes much to employees' perception of freedom and autonomy:

We have a ping-pong table here and the employees use it to relax. It's great to know that if you need to get away for a few minutes you can, and no one will get upset with you.

Office layout and access to resources were, respectively, the second and the third most frequently mentioned physical characteristics of the work environment associated with freedom. Employees of Organization D gave some evidence of the presence of these influential factors to freedom in their work environment:

Management is located in front offices, away from the work flow. Little control felt. We are all provided with the tools to perform our various duties. For example, each cubicle has a $P C$ and printer. Fax machines, digital fax, and copiers are close at hand.

It is rather surprising that the physical environment of Organization B, a large-scaled complex with a variety of common facilities, was perceived to be least conducive to freedom among all research sites. Organization $B$ is also significantly less conducive to freedom than both Organizations $C$ and $D$. One observation helps rationalize the results: a majority of descriptive comments given by employees of Organization B focused upon their departmental work areas; only a handful mentioned the entire corporate environment. This observation is consistent with the theoretical premise that freedom is a social-psychological dimension conducive to creativity that is perceived at the individual, task-related level; therefore, freedom is more likely to be influenced by the more immediate physical environment, both in terms of scale and features. Any available corporate facilities outside the departmental areas can be considered rather psychologically remote, and thus, have diluted effects on employees' perception of the physical work environment. This justification implies the greater contribution of individuals' immediate physical environment-the task-related spaces over which they are enabled to control and personalize-to creativity rather than the remote, public environment.

This study identified specific attributes of the physical environment perceived to most frequently support dynamism and freedom (summarized in Table 8). While the effects of the physical setting are often criticized on the basis that other social-psychological factors are more important, this study asserts that the physical work environment is perceived as a constituent of organizational climate for creativity. It is found to operate in tandem with the social-psychological work environment to foster creative behavior in organizations. Yet no conclusion can be drawn about: (a) how significant the contribution of the physical work environment is to creativity if the coeffect of the social-psychological environment were separated out; and (b) how significant the contribution of the physical environment is in comparison to that of the social-psychological work environment. In determining the role of the physical work environment in promoting creativity, this study recognizes that the physical work 
environment does not relate to the social-psychological work environment in a simplistic unidirectional, causeeffect manner but rather a relationship with complex dimensions.

\section{Limitations and Implications for Future Research}

All four participating organizations in this study are publicly acclaimed for their creative operational practices and supportive management policies (the major social-psychological organizational variables); whereas their physical work environments are distinctly different for the purpose of identifying various physical elements and attributes associated with creativity. Therefore, the research findings can only be representative of creativity in organizational settings in which all participating organizations are publicly acknowledged as highly creative and possess exceptional management support for creativity; applying the findings to other organizations that differ from the research sites in the respective terms would require special caution. Consequently, generalizability of the research findings is limited.

Future research with ample time and resources could consider a sampling strategy that compares diverse groups of participating organizations categorized by the dichotomies of their social-psychological and the physical work environments (more conducive, less conducive to creativity). This suggested sampling includes in the research design a control group that is less conducive to creativity in both the social-psychological and the physical work environments. While this study investigated creativity across disciplines, discipline-specific research would potentially yield further insight into how environments supportive of creativity differ from field to field. Although the literature supports environmental assessment by means of human perception, the issue of self-report bias arises as a usual threat in constructing the validity of assessment instruments on such a subjective basis. However, the theoretical premise that organizational climate itself is represented by the perceptions of organizational members supports the use of subjective methodologies. Future research may also benefit by using performancebased measures in addition to the self-reported measures utilized in this study. By using an organization's creative output as an external measure of creativity, hypothetical links between the workplace environment and creative success could be tested.

\section{Conclusion}

The relationship between the physical environment and creativity constructed in this study may serve as a theoretical basis for further investigations. It is not the intention of this study to frame a conclusive and comprehensive set of practical implications of the physical work environment for creativity but rather to suggest general guidelines and a tangible direction, based upon theory presented in the fields of organizational behavior and environmental psychology. These findings begin to provide a more defined understanding of creativity as a function of the interrelationships between individuals, organizations, and the physical environment, and the study adds empirical evidence of how the environment and interior design support creativity. It is hoped that these findings will enhance future research and provide the conceptual framework to better integrate the design of the physical environment into an organization's strategic plan for competitiveness and long-term success.

\section{References}

Alencar, E. M. \& Bruno-Faria, M. F. (1997). Characteristics of an organizational environment which stimulate an inhibit creativity. Journal of Creative Behavior, 31[4), 271-281.

Allen, T. (1 969). Meeting the technical information needs of research and development projects (Report No. 13314), MIT Industrial Liaison Program. 
Amabile, T. M. (1998). How to kill creativity. Harvard Business Review (September-October), 77-87.

Amabile, T. M. (1996). Creativity in context. Boulder, CO: Westview.

Amabile, T. M. (1983). The social psychology of creativity. NY: Springer-Verlag.

Basadur, M. (1997). Organizational development interventions for enhancing creativity in the workplace. Journal of Creative Behavior, 3/(1), 59-72.

Becker, F. D. (1981). Workspace: Creating environments in organizations. NY: Praeger.

Betchel, R. B. (1976). Enclosing behavior. Stroudsburg, PA: Dowden, Hutchinson \& Ross.

Clitheroe, H. C, Stokols, D., \& Zmuidzinas, M. (1998). Conceptualizing the context of environment and behavior. Journal of Environmental Psychology, 18, 103-112.

Csikszentmihalyi, M. (1999). Implications of a systems perspective for the study of creativity. In R.J. Sternberg (Ed.), Handbook of creativity. Cambridge, UK: Cambridge University Press.

Csikszentmihalyi, M. (1988). Society, culture, and person: A systems view of creativity. In R.J. Sternberg (Ed.), The nature of creativity. Cambridge, MA: Cambridge University Press.

Cummings, L. (1965). Organizational climates for creativity. Journal of the Academy of Management, 8, 220-227.

Ekvall, G. (1987). The climate metaphor in organization theory. In B.M. Bass \& Drenth, P. (Eds.), Advances in organizational psychology: An International Review. Newbury Park, CA: Sage.

Ekvall, G., ArvonenJ., \& Waldenstrom-Lindblad, I. (1983). Creative organizational climate: Construction and validation of a measuring instrument (Report 2). Stockholm: The Swedish Council for Management and Organizational Behavior.

Ekvall, G., \& Tangeberg-Andersson, Y. (1986). Working climate and creativity: A study of an innovative newspaper office. Journal of Creative Behavior, 20(3), 215-225.

Ferguson, S. D. \& Ferguson, S. (1988). The physical environment and communication. In S.D. Ferguson \& S. Ferguson (Eds.), Organizational communication (2nd ed. |. New Brunswick, NJ: Transaction.

Fischer, W. A., \& Faar, C. M. (1985). Dimensions of innovative climate in Chinese R\&D units. R\&D Management, 75(3), 183-190.

Gruber, H. (1988). The evolving systems approach to creative work. Creativity Research Journal, [[]), 27-51.

Guilford, J. P. (1967). The nature of human intelligence. NY: McGraw-Hill.

Guilford, J. P. (1950). Creativity. The American Psychologist, 5(9), 444-454.

Hitt, M. A. (1975). The creative organization: Tomorrow's survivor. Journal of Creative Behavior, 9(4), 283-290.

Kanter, R. M. (1988). When a thousand flowers bloom: Structural, collective, and social conditions for innovation in organizations. Research in Organizational Behavior, 10, 169-21 1.

Litwin, G. H., \& Stringer, R. A. (1968). Motivation and organizational climate. Boston: Division of Research, Graduate School of Business Administration, Harvard University.

Mackinnon, D. W. (1962). The nature and nurture of creative talent. American Psychologist, 17, 484-495.

Magnusson, D. (1981). Wanted: A psychology of situations. In D. 
Magnusson (Ed.), Toward a psychology of situations: An international perspective. Hillsdale, NJ: Lawrence Erlbaum. Mumford, M. D., \& Gustafson, S. B. (1988). Creativity syndrome:Integration, application and innovation. Psychological Bulletin, 103, 27-43.

Mumford, M. D., \& Simonton, D. K. (1997). Creativity in the workplace: People, problems, and structures. Journal of Creative Behavior, 3/(1), 1-6.

Nystrom, H. (1979). Creativity and innovation. Chichester: John Wiley \& Sons.

Oldham, G., \& Brass, D. (1979). Employee reaction to an openplan office: A naturally occurring quasi-experiment. Administrative Science Quarterly, 24, 267-284.

Osmond, H. (1966). Some psychiatric aspects of design. In L. Holland (Ed.), Who designs America? NY: Anchor.

Proshansky, H. M., Ittelson, W. H., \& Rivlin, L. G. (1970). Freedom of choice and behavior in a physical setting. In H.M. Proshansky, W. H. Ittelson \& L. G. Rivlin (Eds.), Environmental psychology: Man and his physical setting. New York: Holt, Rinehart and Winston.

Rickards, T., \& Bessant, J. (1980). The creativity audit: Introduction of a new research measure during programs for facilitating organizational change. R\&D Management, 70(2), 67-75.

Rhodes, M.(1961). An analysis of creativity. Phi Delta Kappa, 42, 305- 310.

Schein, E. H. (1990). Organizational cullure. American Psychologist, 45, 109-119.

Siegel, S. M., \& Kaemmerer, W. F. (1978). Measuring the perceived support for innovation in organizations, journal of Applied Psychology, 63(5), 553-562.

Sommer, R. (1974). Tight spaces: Hard architecture and how to humanize it. Englewood Cliffs, I(]: Prentice-Hall. Steele, F. I. (1973). Physical settings and organization development. Reading, MA: Addison-Wesley.

Sundstrom, E. (1986). Work places: The psychology of the physical environment in offices and factories. Cambridge, MA: Cambridge University Press.

Tesluk, P., Farr, J., \& Klein, S. (1997). Influences of organizational culture and climate on individual creativity. Journal of Creative Behavior, 31(1), 27-41.

Author's Note

This research was made possible in part through the generous support of the International Interior Design Association Foundation/Steelcase Fellowship program for which the authors are extremely grateful. The authors would also like to acknowledge Jason Meneely for his significant efforts in editing the manuscript in preparation for publication submission. 